\title{
Solid-Meal Gastric Emptying Study
}

\section{Kathy S. Thomas and Mary Beth Farrell}

$\mathbf{T}$ ment of gastric function and motility using a standardized mealand-imaging protocol.

\section{CLINICAL INDICATIONS (2)}

- Evaluation of dyspepsia (pain in the upper abdomen, nausea, vomiting, belching, bloating, distension, fullness, or early satiety).

- Evaluation of gastroparesis (delayed gastric emptying or stasis).

- Evaluation of mechanical or anatomic obstruction.

- Evaluation of weight loss.

\section{CONTRAINDICATIONS}

- Pregnancy and/or breast feeding.

- Allergy to eggs or any component of the meal.

- Hypoglycemia (blood glucose level $<40 \mathrm{mg} / \mathrm{dL}$ ).

- Hyperglycemia (blood glucose level $>200 \mathrm{mg} / \mathrm{dL}$ ).

- Recent nuclear medicine study.

\section{PATIENT PREPARATION/EDUCATION/FOOD/MEDICATION RESTRICTIONS}

- Patients should be told to take no food or liquids by mouth for 4-6 h before the study.

- Premenopausal women should be scheduled for imaging during the first $10 \mathrm{~d}$ of the menstrual cycle.

- Blood glucose should be measured and recorded (insulin-dependent patients should be instructed to adjust their insulin dose so that their measured blood glucose level is $<200 \mathrm{mg} /$ dL).

- Patients should be told not to smoke the morning of the test and until the examination is complete.

- A focused history should be taken of past and current diseases, interventional or surgical procedures, and medications.

- Patients should be given a detailed description of the study, including the requirement to consume the solid gastric emptying meal within $10 \mathrm{~min}$, the total time for the procedure and for each imaging session, the position they will be placed in during imaging, and the activity restrictions they will have to follow between imaging sessions.

- Patients should confirm that they have discontinued any restricted medications as directed by the referring physician (Table 1).

\section{PROTOCOL/ACQUISITION INSTRUCTIONS}

- Prepare and administer the solid meal (Tables 2 and 3).

- Have the patient eat the meal as a sandwich or as individual items within $10 \mathrm{~min}$. (If the patient cannot eat at least $50 \%$ of the meal, the gastric emptying results may be overestimated, resulting in a nondiagnostic study.)

COPYRIGHT (C) 2019 by the Society of Nuclear Medicine and Molecular Imaging.
- Record the amount of time required to consume the meal, the percentage of the meal consumed, and any issues associated with meal consumption (e.g., vomiting).

- Begin the image acquisition (Table 4) immediately in the upright anterior/posterior position with the distal esophagus, stomach, and proximal small intestine in the field of view. Acquire simultaneous images on a dual-head $\gamma$-camera and sequential images on a single-head $\gamma$-camera. Acquire delayed images at 1, 2, 3, and $4 \mathrm{~h}$. Position a ${ }^{57} \mathrm{Co}$ marker at the xyphoid process to help in positioning the patient for follow-up images. Acquire all followup images on the same $\gamma$-camera as that used for the initial postmeal image.

- If the patient cannot stand, substitute supine images in the left anterior oblique (LAO) position on a single-head $\gamma$-camera or supine images in the anterior/posterior position on a dual-head $\gamma$-camera.

- Recommend minimal activity between imaging sets: encourage the patient to sit comfortably in the waiting room and avoid any strenuous activity.

\section{TABLE 1}

Medications to Discontinue 48-72 h Before Gastric Emptying Scintigraphy $(1,3)$

\begin{tabular}{|c|c|}
\hline Class of agent & Generic medication name \\
\hline \multirow[t]{4}{*}{ Prokinetics } & Metoclopramide \\
\hline & Cisapride \\
\hline & Domperidone \\
\hline & Erythromycin \\
\hline \multirow{4}{*}{$\begin{array}{l}\text { Anticholinergics/ } \\
\text { antispasmodics }\end{array}$} & Dicyclomine \\
\hline & Donnatal \\
\hline & Hyoscyamine \\
\hline & Glycopyrrolate \\
\hline \multirow[t]{3}{*}{ Opiate analgesics } & Meperidine \\
\hline & Codeine \\
\hline & Morphine, oxycodone \\
\hline \multicolumn{2}{|l|}{ Antidepressants } \\
\hline \multicolumn{2}{|l|}{ Calcium channel blockers } \\
\hline \multicolumn{2}{|l|}{$\begin{array}{l}\text { Gastric acid suppressants/ } \\
\text { aluminum-containing } \\
\text { antacids }\end{array}$} \\
\hline \multicolumn{2}{|l|}{ Laxatives* } \\
\hline \multirow{5}{*}{$\begin{array}{l}\text { Agents that may affect } \\
\text { gastric emptying }\end{array}$} & Atropine \\
\hline & Nifedipine progesterone \\
\hline & Octreotide \\
\hline & Theophylline \\
\hline & Benzodiazepine phenylamine \\
\hline
\end{tabular}

${ }^{*}$ Discontinue for $24 \mathrm{~h}$ beforehand. 
TABLE 2

99mTc-Sulfur Colloid Dose for Solid Gastric Emptying Meal

\begin{tabular}{lc}
\hline Age group & \multicolumn{1}{c}{ Administered activity } \\
\hline Adults & $18.5-37 \mathrm{MBq}(0.5-1.0 \mathrm{mCi})$ orally \\
Children & $9.25-18.5 \mathrm{MBq}(0.25-0.5 \mathrm{mCi})$ orally \\
\hline
\end{tabular}

TABLE 3

Ingredients and Cooking Method for Solid Gastric Emptying Meal

\begin{tabular}{ll}
\hline \multicolumn{1}{c}{ Ingredient } & \multicolumn{1}{c}{ Amount } \\
\hline Liquid egg whites* & $120 \mathrm{~g} \mathrm{(4} \mathrm{oz)}$ \\
\hline White bread & 2 slices \\
Strawberry jam & $30 \mathrm{~g} \mathrm{(} \mathrm{1} \mathrm{tablespoon)}$ \\
Water & $120 \mathrm{~mL}(4 \mathrm{oz})$ \\
& \\
\hline *For example, Egg Beaters (99\% real eggs, cholesterol-free, \\
fat-free, and low-calorie; Conagra Brands). \\
Mix egg white with 99mTc-sulfur colloid and cook in microwave \\
$\begin{array}{l}\text { or nonstick griddle. Stir once or twice during cooking and cook } \\
\text { until texture is of a firm omelet. Toast bread and spread with jelly. }\end{array}$ \\
\hline
\end{tabular}

\section{IMAGE PROCESSING}

- Quantify gastric emptying by drawing regions of interest around the stomach on all anterior and posterior images. The ROI should include any visualized activity in the fundus and antrum of the stomach. Whenever possible, adjust the ROI to avoid activity in the loops of the small bowel.

- Apply radioactive decay correction for the ${ }^{99 \mathrm{~m}} \mathrm{Tc}$ to the final results.

- Calculate the geometric mean of the anterior/posterior images (square root of the product of the anterior counts multiplied by the posterior counts $(\sqrt{ }[$ anterior counts $\times$ posterior counts $])$.

- Display the final results as percentage remaining in the stomach for each image set, with the total gastric counts
TABLE 4

Standard SPECT Acquisition Parameters

\begin{tabular}{ll}
\hline \multicolumn{1}{c}{ Parameter } & \multicolumn{1}{c}{ Details } \\
\hline Camera type & Large-field-of-view multidetector \\
\hline Energy peak & $140 \mathrm{keV}$ \\
\hline Energy window & $20 \%$ \\
\hline Collimator & Low-energy high-resolution \\
\hline Patient position & $\begin{array}{l}\text { Upright if possible or in the supine } \\
\text { (dual-head) or LAO (single- } \\
\text { head) position }\end{array}$ \\
\hline Camera position & \\
\hline Dual-head camera & Anterior for detector 1 \\
\hline Single-head camera & Posterior for detector 2 \\
\hline Injection to scan time & Immediate \\
\hline Acquisition type & Planar \\
\hline Views & Initial, $1 \mathrm{~h}, 2 \mathrm{~h}, 3 \mathrm{~h}, 4 \mathrm{~h}$ \\
\hline Matrix & $128 \times 128$ \\
\hline Time per view & $60 \mathrm{~s}$ \\
\hline
\end{tabular}

normalized to $100 \%$ for time $\mathrm{T}=0$ (first image set after the meal).

- Generate a time-activity curve from the geometric mean of gastric counts displayed for all time points.

\section{REFERENCES}

1. Farrell MB, Mantel ES, Basso DA, et al. The gastrointestinal system, gastric emptying study—solid meal. In: Quick Reference Protocol Manual for Nuclear Medicine Technologists. Reston, VA: Society of Nuclear Medicine and Molecular Imaging; 2014:156-159.

2. Procedure guideline for adult solid-meal gastric-emptying study 3.0. SNMMI website. http://snmmi.files.cms-plus.com/docs/Guideline\%20for\%20Adult\%20Gastric \%20Emptying.pdf. Published 2009. Accessed March 11, 2019.

3. Bolus N, Farrell MB, Zimmerman J. Gastric emptying scintigraphy. In: Abdominal Imaging 2017: Quality, Safety and Dose Optimization. Reston, VA: Society of Nuclear Medicine and Molecular Imaging; 2017:22-41. 